\title{
LESSONS FROM PHILIPPINES MPA MANAGEMENT: SOCIAL ECOLOGICAL INTERACTIONS, PARTICIPATION, AND MPA PERFORMANCE
}

\author{
Julia Twichell, Richard Pollnac, \& Patrick Christie \\ This is a pre-print of an article published in Environmental Management. The final authenticated version is \\ available online at: https://doi.org/10.1007/s00267-018-1020-y
}

J. Twichell (corresponding author) $\cdot$ R. Pollnac

University of Rhode Island, Department of Marine Affairs

Coastal Institute, 1 Greenhouse Road, Kingston, RI 02881-2020, United States

Email: julia_twichell@uri.edu

Telephone: (978) 660-2603

ORCiD: 0000-0001-8895-8165

P. Christie

University of Washington, School of Marine and Environmental Affairs and the Jackson School of International Studies

3707 Brooklyn Avenue NE, Seattle, WA 98105-6715, United States

Acknowledgements:

This work relied on the effort and talent of a diverse team and the good will of hundreds of informants.

The findings of the Learning Project are those of University of Rhode Island and University of Washington and do not necessarily reflect opinions of U.S. Agency for International Development (USAID) or the nongovernmental partners of Conservation International, the Nature Conservancy or the World Wildlife Fund (WWF). While the largest portion of financial support for this project came from USAID through WWF, additional USAID support was provided through Tetra Tech, the National Oceanographic and Atmospheric Administration, and the National Marine Sanctuary Foundation. 


\section{ABSTRACT}

International interest in increasing marine protected area (MPA) coverage reflects broad recognition of the MPA as a key tool for marine ecosystems and fisheries management. Nevertheless, effective management remains a significant challenge. The present study contributes to enriching an understanding of best practices for MPA management through analysis of archived community survey data collected in the Philippines by the Learning Project (LP), a collaboration with United States Coral Triangle Initiative (USCTI), United States Agency for International Development (USAID), and partners. We evaluate stakeholder participation and social ecological interactions among resource users in MPA programs in the Palawan, Occidental Mindoro, and Batangas provinces in the Philippines. Analysis indicates that a complex suite of social ecological factors including demographics, conservation beliefs, scientifically correct knowledge, perceptions of personal benefit, and perceptions of fish scarcity influence participation, which in turn is related to perceived MPA performance. Findings indicate positive feedbacks within the system that have potential to strengthen perceptions of MPA success. The results of this evaluation provide empirical reinforcement to current inquiries concerning the role of participation in influencing MPA performance.

\section{KEYWORDS}

marine protected area $\cdot$ participation $\cdot$ MPA performance $\cdot$ social-ecological system $\cdot$ Philippines

\section{INTRODUCTION}

Marine protected areas (MPAs), also referred to as marine sanctuaries, marine reserves, and notake zones, have been applied worldwide as a key tool in marine conservation and fisheries management (Juffe-Bignoli et al. 2014). The use of MPAs as a management tool continues to be substantiated by research confirming that MPAs maintain and improve ecological outcomes (e.g. Lester et al. 2009; Evans et al. 2008; Russ et al. 2003; Roberts et al. 2001). MPAs additionally have the potential to provide benefits to coastal communities by sustaining and augmenting ecosystem services from coastal ecosystems (Sala et al. 2013; Cabigas et al. 2012).

Unfortunately, research shows that many MPAs fail to achieve environmental objectives due to social factors, stakeholder conflict, and ineffective implementation (e.g. Agardy et al. 2011; Christie et al. 2009; Christie 2004; Mascia 2003). Thus, the challenge for initiatives that seek to increase global MPA coverage lies in implementing and managing these areas effectively. Research targeted at contributing to a greater understanding of successful MPA implementation and management is of paramount importance. This study examines MPA management in the tropical context of the Philippines, where extractive practices are generally prohibited within MPA boundaries.

A growing body of empirical research has identified socioeconomic factors that contribute to MPA success in decentralized management approaches. Pollnac et al. (2001) determined six factors that most reliably predicted success among a sample of 45 community-based MPAs in the Philippines. These factors include small population size, perceived scarcity in the resources targeted, strong alternative livelihood initiatives, strong public participation in governance and decision-making, continued support from participating agencies, and municipal government support. Additionally, perceptions of clear leadership, networking, and educational programs have been found to contribute to social and ecological success (Pietri et al. 2009). Positive biological outcomes have been linked with community support of MPAs and enforcement (Walmsley and White 2003; Cabigas et al. 2012). Good enforcement should be a critical focus for MPA management to ensure compliance with rules and regulations (Christie et al. 2009). Notably, while compliance is related to reserve success, compliance is predicted not simply by strength of enforcement, but also by a range of complex social conditions and processes, such as marine reserve features (e.g. clearly defined boundaries) and involvement in monitoring, training, and the planning process (Pollnac et al. 2010). The strong role of communities, local actors, and stakeholders in determining MPA performance has clearly emerged as a theme that unifies this research.

Increasingly, scholars and practitioners recommend approaches that involve local capacity building and project participation, suggesting that these approaches have greater success (e.g. Christie et al. 2009; 
Chuenpagdee et al. 2013). Since around the year 2000, public participation has garnered increasing acceptance as a fundamental tool for good management. For example, Mascia (2003) presented a review of findings from the ninth International Coral Reef Symposium in 2000 that included recommendations for participatory decision-making, planning, research and monitoring. Participatory processes were also cited as an explanation for increased biological success in Philippine MPAs (Russ and Alcala 1999).

Although participatory approaches have received increased mention in the literature as well as increasing funds and heightened attention from practitioners, few studies have empirically assessed its utility in MPA management. In fact, scholars have noted the need for empirical evaluations of the impacts and implications of project participation (e.g. Gurney et al. 2016; Dalton et al. 2012; Rowe and Frewer 2000). The dominant assumption is that participation influences support and advocacy for conservation initiatives. If this is true, promoting project participation may be one arrangement through which communities can take an integral and lasting role in successfully maintaining their own resources.

Studies of participation typically address stakeholder engagement in the design and planning process (e.g. Webler et al. 2001). Rowe and Frewer (2000) describe the spectrum of stakeholder participation, from passive "communication" methods, such as informational campaigns, to "consultative" involvement in the design and planning process, which might include collection of public opinion or a more dynamic process that emphasizes information exchange. Opportunities for "consultative" participation may be offered in the form of public hearings, citizen advisory committees, or public workshops (Chess and Purcell 1999). Processes encouraging higher quality process participation have been shown to result in higher quality environmental decision-making (Reed 2008).

Participation may also include physical involvement in monitoring, enforcement, training, and advocacy. Citizen science monitoring programs, for example, are increasingly employed in marine environmental management to enable large-scale data collection and empowerment of citizens. Citizen science approaches have demonstrated positive impacts on attitudes toward science (Price and Lee 2013), environmental and scientific knowledge (e.g. Crall et al. 2013; Brossard et al. 2005), environmental awareness and concern (Branchini et al. 2015; Johnson et al. 2014), and pro-environmental behavior and advocacy (Johnson et al. 2014; Toomey and Domroese 2013). Participatory action-research efforts also provide an opportunity for disempowered social groups to explore the underpinnings of environmental and social problems in terms that they define, through information they gather, resulting in direct action and social learning (Trimble and Lázaro 2014, Mackenzie et al. 2012, Muro and Jeffrey 2008, Christie et al. 2000).

Participatory methods have been developed and implemented in developing country contexts. Pollnac et al. (2001) found that high participatory democracy in MPA decision-making as well as project participation (Pollnac and Seara 2011) were important factors contributing to MPA success in the Philippines. Weeks et al. (2014) compiled best practices from six case studies in the Coral Triangle Initiative on Coral Reefs, Fisheries, and Food Security (CTI-CFF) MPA system that included use of participatory mapping, community training in mapping software, and participatory biological monitoring and enforcement programs. Dalton et al. (2012) found no direct causal link between participation and perceived positive MPA outcomes or MPA support; however, their findings indicated that the quality of the MPA process likely influenced how participation related to these factors. This research extends this line of inquiry through an evaluation of participatory approaches in a tropical MPA context.

The present study analyzed archived ex post social surveys conducted by the Learning Project (LP), a collaboration with United States Coral Triangle Initiative (USCTI), United States Agency for International Development (USAID), and partners. The surveys contributed to a general analysis of MPAs in villages in the Philippines. Some of the MPAs received technical support from CTI-CFF; however, in most cases, there were multiple projects, non-governmental organizations, and/or donors supporting each MPA. Specifically, this study examined relationships among social ecological factors that may influence resource users' project participation in MPA and conservation programs, in order to increase understanding of best management practices for tropical marine protected area management. We additionally analyzed the hypothesized effect of participation upon perceptions of MPA performance. Our findings provide empirical reinforcement to the continuing dialogue regarding social ecological interactions, MPA performance, and MPA management (e.g. Gurney et al. 2016; Gutiérrez et al. 2011; Mascia 2003; Cinner 2007; Chuenpagdee et al. 2013; Pollnac and Seara 2011; Christie et al. 2009; Pomeroy et al. 2005; White et al. 2002). 


\section{METHODS}

\section{Sampling}

Archived LP social survey data were analyzed from 15 villages in the Palawan, Occidental Mindoro, and Batangas provinces in the Philippines that were associated with an MPA (Figure 1).

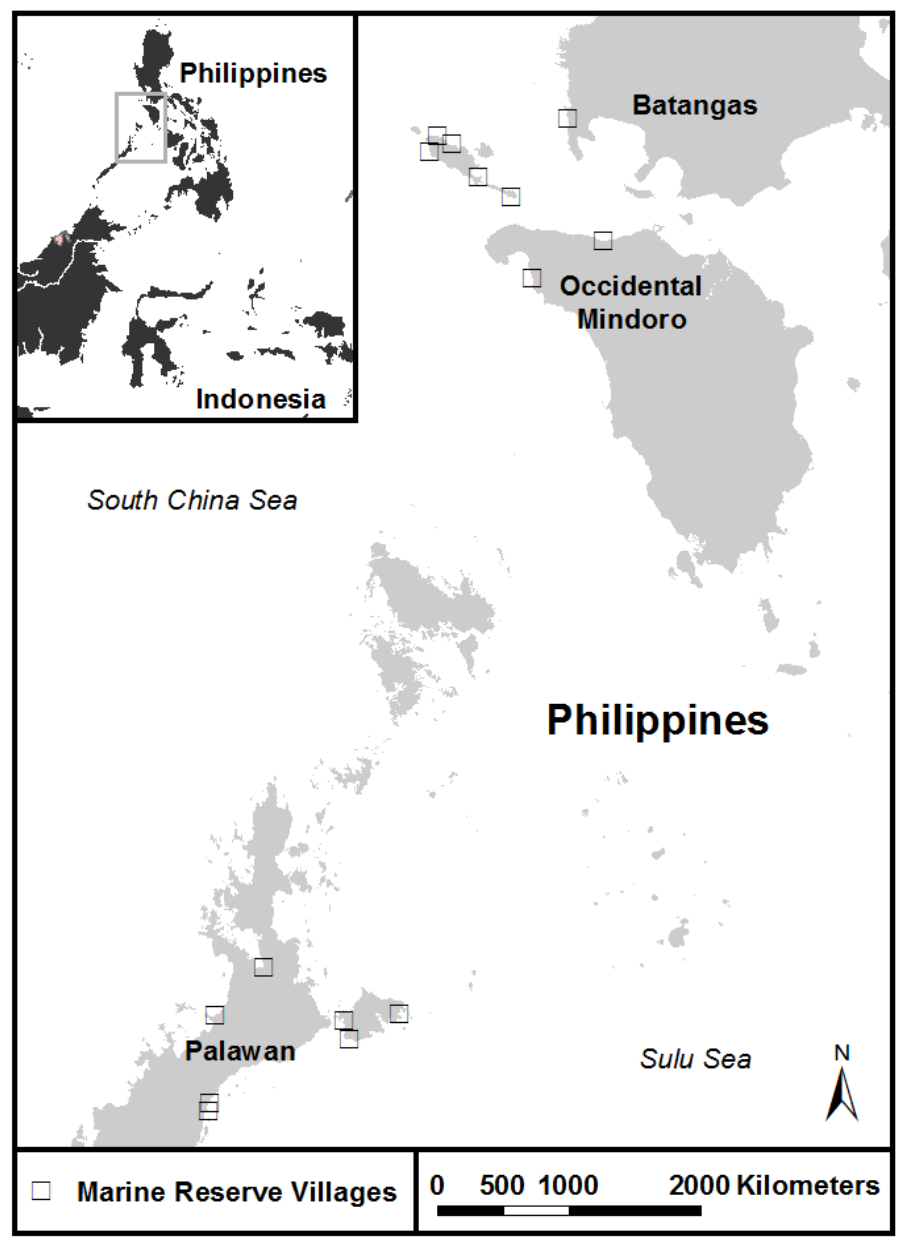

Fig. 1 Map of study sites in the Batangas, Occidental Mindoro, and Palawan provinces in the Philippines (Basemap Source: National Geographic World Map; Software: ESRI ArcMap)

214 resource users, all screened for MPA awareness (Is there a marine sanctuary in your community? Yes $=1$, No $=0$ ), were asked to participate in an in-person structured community survey. Resource users responded to questions about gender, age, and years of education as well as involvement in conservation programs, conservation beliefs, and perceptions of resource and ecological conditions. Respondents were asked additional questions regarding perceptions of MPA performance and process as well as personal involvement.

The literature is mixed with regard to the relationship between gender and participation. Some find that gender is unrelated to citizen science participation (e.g., Martinez et al. 2004), yet others note that men are more likely to participate in MPA planning and management than women (Smith et al. 2012; Dalton et al. 2012). The latter studies evaluate gender and participation in developing country contexts, where gender roles are more similar to those in the Philippines. This study tests the hypothesis that men are more likely to participate in MPA- and conservation-related activities than women.

McClanahan et al. (2005) found that secondary education related to more positive perceptions of benefits from MPA management. Other studies have not found links between educational attainment and MPA support (Hoelting et al. 2012) or decisions to volunteer in citizen science (Martinez and McMullin 
2004). Several studies have found that age is not related to perceived benefits from MPAs (McClanahan et al. 2005), acceptance of MPAs (Hamilton 2012), decisions to participate (Dalton et al. 2012), or volunteer involvement (Martinez 2004). Smith (2012), however, found that participation and the belief that MPA management has represented one's views increases with age.

\section{Measures}

Participation Measures: This paper's definition of project participation includes active project-related participation and consultative participation. Active participation includes monitoring, enforcement patrols, illegal conduct reporting, participating in climate change and ocean awareness activities, and attending topical trainings (Box 1: 1-5). Consultative participation was measured using two survey questions that targeted respondents' perceptions that their personal views were considered during the MPA planning process and also if they thought the community was consulted during the MPA planning process (Box 1: 67). Not all participation included direct involvement with the village MPA; however, general involvement in conservation efforts that are related to ecosystem and fisheries management as well as ecosystem monitoring and enforcement can be considered to be highly related processes. Building conservationrelated capacity is an opportunity to broaden support for and trust in conservation initiatives, including the establishment and success of MPAs.

\section{Participation Variables}

Active Participation

1. Have you been involved in monitoring sanctuary conditions? $($ Yes $=1, \mathrm{No}=0)$

2. Have you ever participated in sea watch patrols? $(\mathrm{Yes}=1$, No $=0)$

3. Have you ever reported someone using illegal fishing methods or coastal activities? (Yes $=1$, No $=0)$

4. Have you participated in activities that raise public awareness about the conditions of the ocean and/or climate change? (i.e. media campaigns, videos, presentations)? (Yes $=1, \mathrm{No}=0)$

5. What type of marine resources management training have you received? Climate Change Training ( $\mathrm{Yes}=1, \mathrm{No}=0$ )

Marine Protected Areas Training ( $\mathrm{Yes}=1, \mathrm{No}=0)$

Fisheries Management Training ( $\mathrm{Yes}=1, \mathrm{No}=0)$

Consultative Participation

6. Were the community members consulted when the sanctuary was planned? $($ Yes $=1$, No $=0)$

7. To what extent were your views considered during the sanctuary planning process? (The planning process considered none of my views $=1$, The planning process considered some of my views $=2$, The planning process considered all my views $=3$ )

Box 1 Participation variables

Magnitude of participation was measured using a standardized participation index where participation measures 1-7 were standardized and summed to produce a composite participation score for each respondent. Scale reliability of the resulting variable was high (Cronbach's $\alpha=0.717$, No. of items $=$ 7). Respondents scoring higher in the participation index participated in more than one capacity and those with the lowest scores did not participate at all. Participation index scores were not normally distributed; hence, non-parametric tests were used for all relevant analyses.

Conservation Belief Scales: Conservation beliefs were measured using a 9-question conservation belief scale. Conservation beliefs were evaluated using Likert scales scored from 1 to 5 such that higher numbers denoted beliefs that align more closely with Western conservation thinking and lower numbers were the 
opposite (Disagree Strongly $=1$, Disagree $=2$, Unsure $=3$, Agree $=4$, Agree Strongly $=5$ ). A factor analysis (a principal component analysis (PCA) with varimax rotation) was performed for the 9 variables, reducing 8 of the indicators into 2 factors that reflect patterns and interrelationships in beliefs (Table 1). One indicator (Farming in the village can have an effect on the fish) was not used in the final PCA because of loading below 0.40 . The number of factors was determined using a scree test.

Table 1 Rotated component matrix of conservation beliefs in villages with MPAs (component loadings)

\begin{tabular}{lcc}
\hline \multicolumn{1}{c}{ Variable } & Control & Vastness \\
& & \\
We must take care of land and sea & 0.728 & -0.023 \\
Clearing away coral does not improve fishing & 0.717 & 0.107 \\
If we work together we can protect our resources & 0.668 & 0.019 \\
The ocean will not carry garbage away & 0.720 & 0.117 \\
Protecting mangroves protects small fish & 0.591 & 0.050 \\
God will not take care of the air and sea & -0.022 & 0.778 \\
There will not always be many fish & 0.015 & 0.650 \\
Human activities influence the number of fish & 0.161 & 0.604 \\
& & \\
Percent total variance & 29.792 & 17.770 \\
\hline
\end{tabular}

Component loadings were used to define each reduced factor. The first factor, "Control," connotes the idea that humans can manage and control their impact on the ocean environment. The "Control" beliefs component reflects the concept of self-efficacy, or the belief in one's ability to manage environmental impacts through personal action (Johnson et al. 2014). The second factor, "Vastness," relates to the perception that the ocean is vast and thus immutable. Although these factors may appear to represent opposing ends of the same scale, the "Vastness" factor likely relates to cultural beliefs that affect the way respondents define the ocean as an entity and where they define their limits of influence in the natural sphere. Principal component scores were produced for each reduced factor. Higher scores indicate more environmentally correct beliefs.

Inclusion of Nature in Self-Identity: Individuals that include nature in their self-identity have been found to report more pro-environmental behaviors (Davis et al. 2009). A pictorial diagram, adapted from Davis et al. (2009), was used to measure an individual's concept of their own relationship with nature. The diagram depicted seven choices of same-size paired circles that ranged in magnitude of overlap from no overlap to almost fully overlapped (Figure 2). Respondents were asked to choose one picture to represent their connectedness with nature. Pictures were coded on an ordinal scale (No Overlap $=1$ to Greatest Overlap $=7)$.

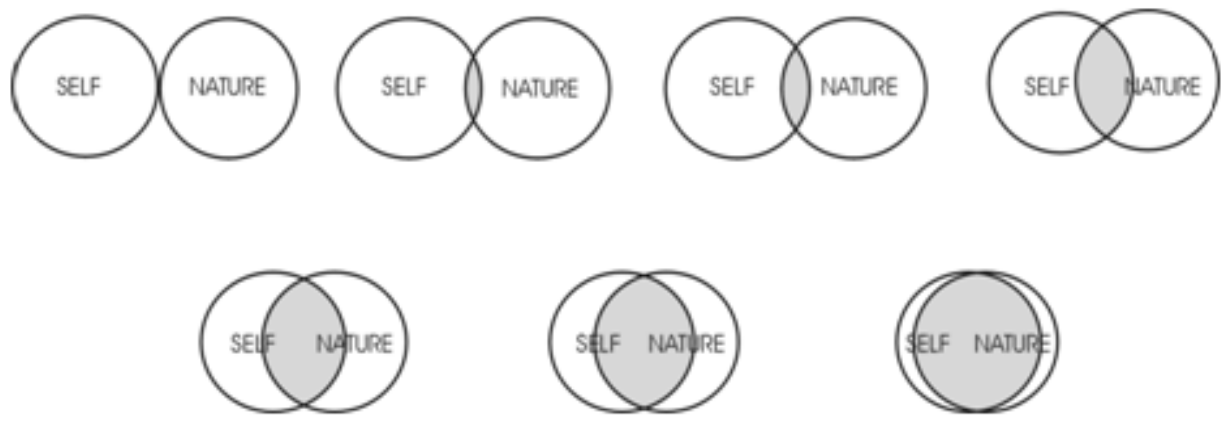

Fig. 2 Diagram of self-identity with nature adapted from Davis et al. (2009) associated with the Community Survey question "Please circle the picture that best describes your relationship with the marine environment (SELF = you, NATURE $=$ the marine environment)" (No overlap $=1$ and Greatest overlap $=7$ ) 
Food and Income Insecurity: Respondents were asked to evaluate the statement "There are no longer enough fish in the sea to provide for our food and income." (Agree $=1$, Disagree $=0$ ).

Scientific Knowledge Scale: Respondents were asked about their perceptions of the value (utility) of coral and mangrove resources using an open-ended format. Responses indicating the utility of coral and mangroves as fish nursery were coded as two separate scientific knowledge variables. Respondents were further evaluated on coral ecology knowledge using an open-ended format in response to the question, "What are corals in your opinion?" "Animal" was considered the scientifically correct response based on scientific classification. Those responses were coded as a third knowledge variable. It should be noted that the most common response was "live rock," likely because the Tagalog word for coral is bato, which also means "rock." This paper does not consider the answer, "live rock," to be incorrect. Few respondents indicated that coral is "dead rock" and many indicated that coral is a plant. This may reflect understanding of the photosynthetic function of zooxanthellae within coral organisms rather than a misidentification of the species.

Using a PCA and scree test, the 3 variables were reduced to a single factor representing the scientific knowledge variable, which explained $46.3 \%$ of the variance (Table 2). Principal component scores were produced for the reduced factor. Higher scores indicate more scientifically correct beliefs.

Table 2 Rotated component matrix of scientific knowledge among resource users

\begin{tabular}{lc}
\hline \multicolumn{1}{c}{ Variable } & Loading \\
& \\
Coral reefs are fish nurseries & 0.767 \\
Mangroves are fish nurseries & 0.759 \\
Coral are animals & 0.475 \\
\hline
\end{tabular}

Personal Benefit from MPA: An index representing perceived benefits from MPAs was created by summing a list of benefits such as fish catch, tourism, pride, alternative livelihood, income, food security, and recreation (Yes $=1$, No $=0$ for all variables). The index was not assumed to represent a latent construct (Netemeyer, Bearden, and Sharma 2003). This paper tests the hypothesis that greater perceived benefits from the marine reserve should positively correlate with both participation and perceived MPA performance.

Perceived MPA Performance: Respondents were asked several questions relating to perceived MPA performance (Box 2). Measures were selected based on research that has previously linked these variables with MPA performance (e.g. Pollnac et al. 2010; Pietri et al. 2009; Hoelting et al. 2013; Christie et al. 2009; Pomeroy et al. 2005).

\section{MPA Performance Variables}

1. In this village, who supports the sanctuary? (Only a few people $=1$, Many people $=2$, The majority of the community $=3$ )

2. Is there a clear leader for the sanctuary? $(\mathrm{Yes}=1, \mathrm{No}=0)$

3. Would you describe the sanctuary management committee as: (Very weak $=1$, Weak $=2$, Average $=3$, Strong $=4$, Very strong $=5$ )

4. Should there be more marine sanctuaries in the area? $(Y e s=1$, No $=0)$

5. Are there clear boundaries for the sanctuary in your village? (Yes $=1$, $\mathrm{No}=0$ )

7. Biological Change Index (A higher score indicates improvement in perceived coral, fish, and mangrove conditions from 2009 to 2013)

Box 2 MPA Performance variables 
The biological change index, representing perceived biological change, resulted from summing reported changes in coral, fish, and mangrove conditions from 2009 to 2013. The index was not assumed to represent a latent construct (Netemeyer, Bearden, and Sharma 2003).

\section{ANALYSIS}

SPSS 21.0 and SYSTAT 13 were used to output Spearman's rank correlations and principal component analyses. Observed relationships among variables and constructed measures were used to develop a heuristic model to depict inferred causal relationships.

\section{Sample Overview}

The majority of survey respondents (66\%) were male and $91 \%$ employed in a marine occupation. Mean education was 8.1 years, and mean age 41 . Survey respondents typically demonstrated strong proenvironmental thinking. Self-identification with nature was high among respondents (Mean $=6.2$, Std. dev. $=1.4$, Range $=1-7, N=214$ ). Resource user scores were skewed to the left for the "Control" beliefs component indicating strong "Control" beliefs in the survey population.

Each sampled village, or barangay, was associated with a single MPA. Information from the elected barangay official in each village indicated that among the fifteen sanctuaries, thirteen were designated for coral protection, nine for fish protection, eight for seagrass protection, six for mangroves protection, and four for "marine life" protection. The majority of MPAs protected more than one ecosystem parameter. MPAs were an average 6.0 years old. Eight MPAs were less than 5-years-old, three were between 6- and 10-years-old, and four were 10-years or older.

The majority of resource users reported positively about MPA performance indicators (Table 3). Only $30 \%$ answered that few in the community support the MPA, while $28 \%$ reported many support, and $42 \%$ reported majority support.

Table 3 Percent non-negative responses to indicators of MPA performance among respondents who knew of the MPA in their village waters

Variable

Is there opportunity to receive equal benefits? Other people receive the same benefits that you do?* Is there a clear leader? Strength of MGMT Committee ${ }^{a}$ Does the community support the MPA? Should there be more MPAs? Clear boundaries

\begin{tabular}{ccc} 
Method & $\begin{array}{c}\text { Percent } \\
\text { non-negative } \\
\text { responses }\end{array}$ & $\boldsymbol{N}$ \\
Yes/No & $62 \%$ & 187 \\
Yes/No & $55 \%$ & 154 \\
Yes/No & $92 \%$ & 191 \\
Likert Scale & $82 \%$ & 188 \\
Likert Scale & $70 \%$ & 201 \\
Yes/No & $66 \%$ & 195 \\
Yes/No & $91 \%$ & 202 \\
\hline
\end{tabular}

* Original negatively worded statement reworded positively

a Likert Scale: "Very weak," "Weak," "Average," "Strong," "Very Strong" - non-negative responses in bold

bLikert Scale: "A few," "Many," "Most" - non-negative responses in bold

Respondents listed a mean of 1.5 benefits that they received from the MPA (Range $=0-7$ ). Most commonly, these included fish catch (54\%), food security (48\%), and income $(37 \%)(N=210)$. Resource users rarely reported benefits from tourism $(1 \%)$, pride $(0.5 \%)$, alternative livelihood $(6 \%)$, or recreation $(1 \%)$.

Pre-project (2009) biological conditions were typically recalled as average or above average in or near sanctuaries; however, few respondents believed that fish abundance, coral or mangrove conditions were exceptional (Table 4). 
Table 4 Perceptions of resource condition, ${ }^{a}$ resource change,$^{b}$ and illegal fishing violations ${ }^{c}$ near the sanctuary

\begin{tabular}{lcc}
\hline \multicolumn{1}{c}{ Variable } & $\begin{array}{c}\text { Recollections from five years prior to } \\
\text { survey (2009) }\end{array}$ & $\begin{array}{c}\text { Observations reported at time of } \\
\text { survey (2013) }\end{array}$ \\
\hline Fish Abundance & $89 \%[1 \%]^{\text {a }}$ & $55 \%[8 \%]^{\text {b }}$ \\
Coral Condition & $88 \%[3 \%]^{\text {a }}$ & $64 \%[9 \%]^{\text {b }}$ \\
Mangrove Condition & $93 \%[1 \%]^{\text {a }}$ & $82 \%[23 \%]^{\text {b }}$ \\
IIlegal Fishing Violations & $81 \%{ }^{c}$ & $52 \%$ c \\
\hline \multicolumn{2}{c}{ a Percent of respondents recalling average or above average resource condition near the sanctuary five years prior to the survey } \\
indicated by percent of non-negative (bolded) responses to Likert Scale: "very poor," "poor," "average," "good," "very good" \\
[Percent of "very good" responses in brackets] \\
b Percent of respondents reporting stable or positive change in condition in the last five years indicated by percent of non-negative \\
(bolded) responses to Likert Scale: "gotten much worse," "a little worse," "no change," "a little improvement," or "a lot of \\
improvement" [Percent of "a lot of improvement" responses in brackets] \\
cPerceptions of pre- and post-project illegal fishing violations within village waters indicated by percent of respondents reporting \\
observations of one or more types of violations
\end{tabular}

The majority of respondents also indicated stable condition or positive change in resource condition from 2009 to 2013. Mangrove condition and change were more frequently described positively compared to coral or fish condition and change. Positive reports of ecological condition and change in or near MPAs corresponded to declining perceptions of illegal fishing violations in village waters.

\section{Characterizing Participants}

$74 \%$ of respondents who knew of the MPA in village waters were involved in one or multiple participatory activities and $26 \%$ were not $(N=214)$. "Active" participation included monitoring (44 individuals, $21 \%)$, sea watch patrols $(38,18 \%)$, voluntary illegal fishing reporting $(32,15 \%)$, climate change training $(20,9 \%)$, MPA training $(27,13 \%)$, and fisheries management training $(31,15 \%)$. Monitoring included assessments of spawning aggregation sites (10 individuals, 5\%), fish abundance (22, 10\%), fish catch (including gleaning) (7, 3\%), mangroves (6,3\%), and coral reefs (20,9\%). $65 \%$ said that the community was consulted during MPA planning and $56 \%$ said the plan reflected some or all of their views.

\section{Interrelationships with Participation}

Analysis of Spearman's rank correlation coefficient (or Spearman's rho) indicated that age and education were positively correlated with participation, whereas gender negatively correlated, indicating that men were more likely to participate at greater magnitudes than women (Table 5). Participation was positively correlated with the "Control" conservation belief factor, self-identity with nature, perceptions of fish scarcity, personal benefits from the MPA, and the scientific knowledge factor. Participation was not correlated with the "Vastness" conservation belief factor. Perceived MPA performance was strongly and positively correlated with magnitude of participation (measured by the participation index). The results from the correlation matrix were used to develop a heuristic model, which is presented in the discussion with interpretation of inferred relationships. 
Table 5 Spearman's rho correlation matrix of all variables

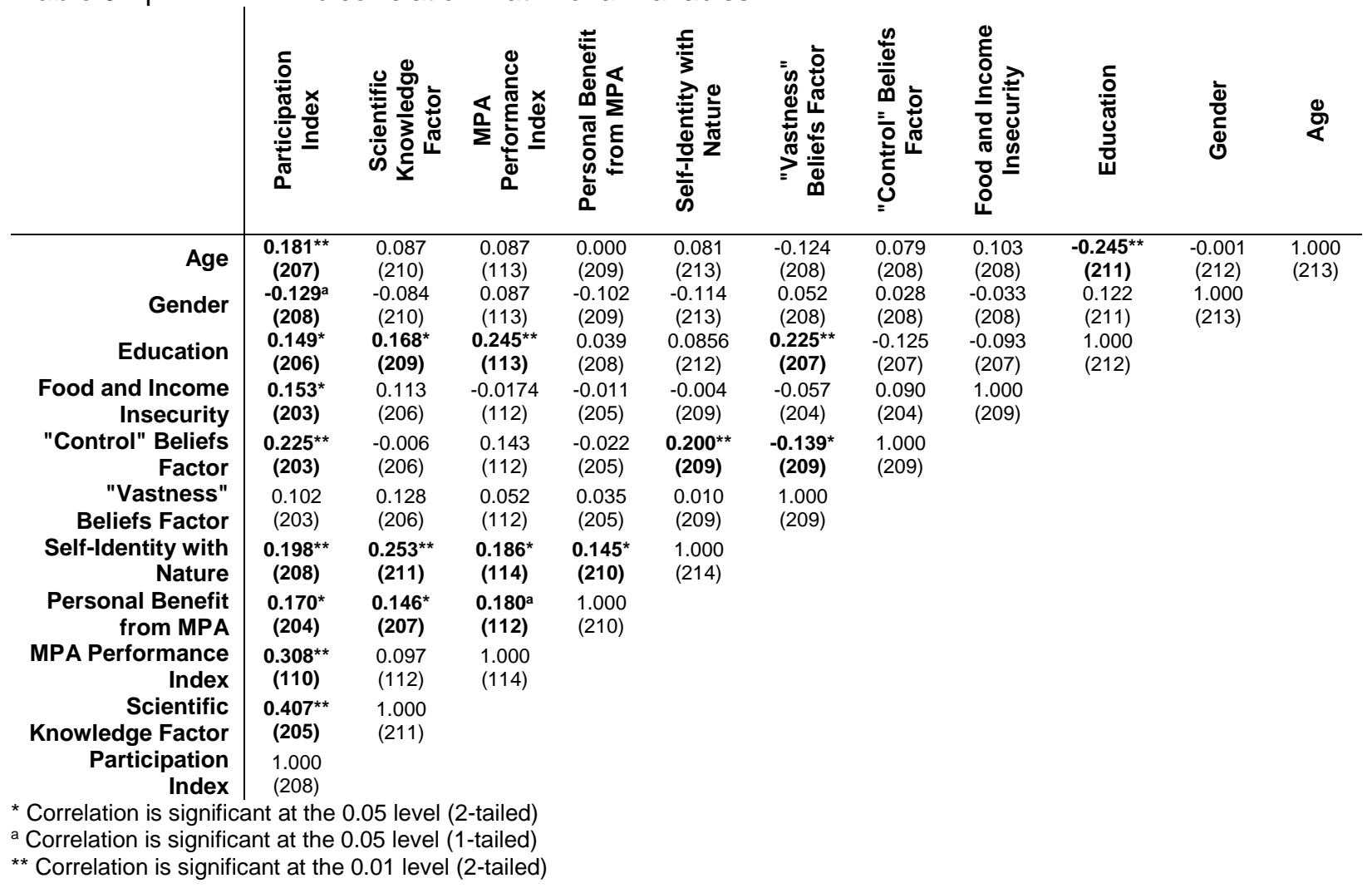

\section{DISCUSSION}

Practitioners increasingly seek to involve stakeholders in MPA planning and management in the interest of improving compliance and support for MPAs. Recent research has explored social factors that influence MPA success, as socioeconomic conditions are often challenges for implementation (e.g. Pollnac et al. 2001; Pomeroy et al. 2005; Cinner 2007; Chuenpagdee et al. 2013). This analysis of social ecological indicators in MPA villages in the Philippines indicates that participation was related to age, education, gender, "Control" beliefs, self-identity with nature, food security, perceptions of personal benefit, and scientific knowledge. These relationships indicate that multiple social factors drive active engagement. Furthermore, these results provide empirical support for the argument that participation may augment MPA performance by building trust, improving perceptions, and aligning resource users' beliefs, knowledge, and perceptions with conservation initiatives in their communities.

Correlations between variables and the interpretations of relationships presented in the following discussion facilitated development of the heuristic model in figure 3 . This model can serve as a hypothesized causal model to be tested in further research, as well as aid in developing our understanding of the complex relationships between these variables and MPA performance. The discussion of the development and testing of causal models in research such as this has had a long history in the social sciences (Simon 1957; Blalock 1964, 1971; Asher 1976). Although we hypothesized relationships between the variables prior to analysis, the configuration of the model derived was not developed prior to the statistical analysis; hence, it is referred to as a heuristic model. 


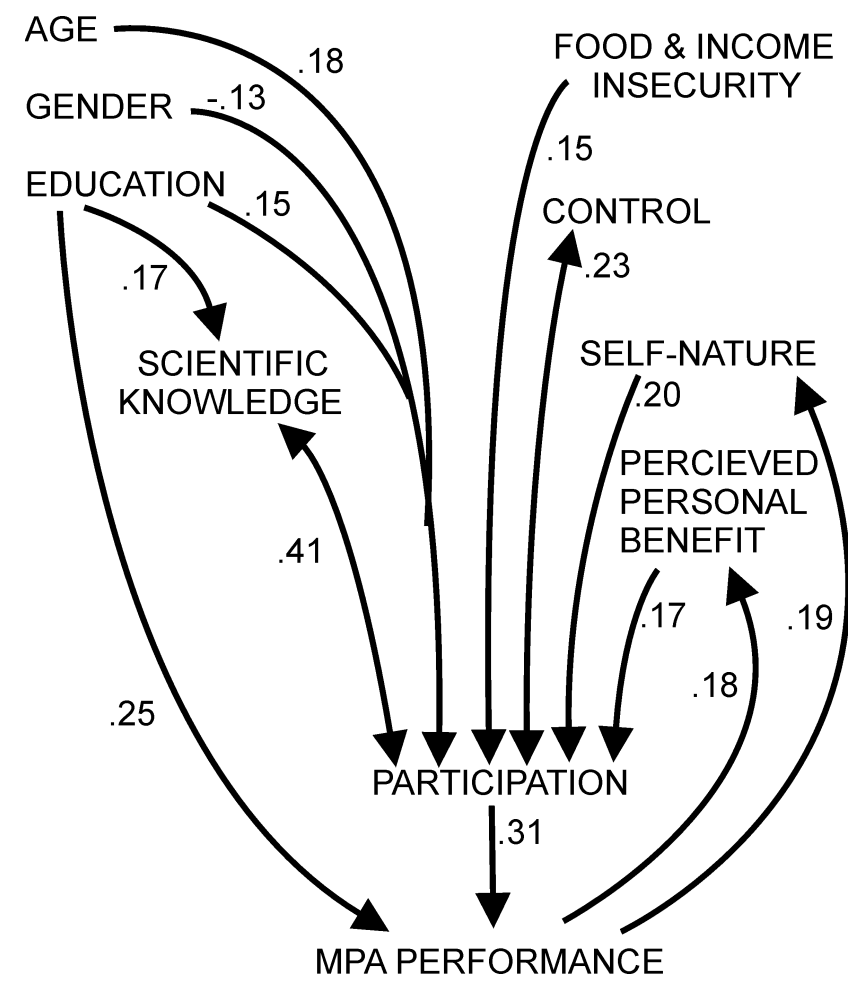

Fig. 3 Heuristic model developed from inferred relationships between variables

Almost three-quarters of the sample of resource users aware of their village MPAs reported participating. This suggests strong interest among resource users in engaging in resource protection and management in the Philippines. However, this study also found men more likely to participate than women. Dalton et al. (2012) also found that resource users, men in particular, were more likely to become involved in MPA initiatives. As men were predominantly fishers in this sample, they presumably had a deep interest in the resources protected by sanctuaries. This divide may also be related to gender differences in project implementation. These findings underscore the need for greater outreach to women as they play an important role in supporting the success of marine conservation initiatives (Ram-Bidesi 2015). This study also found that participation increased with education and age. Because the literature has been mixed with regard to these relationships (McClanahan et al. 2005, Martinez and McMullin 2004, Smith 2012, Dalton et al. 2012), these findings may not be useful as primary factors for guiding outreach to participants. Nevertheless, findings indicate that improving educational opportunities has potential to influence positive feedbacks between participation and perceptions of MPA performance.

Results indicate that resource users were driven by interest in both resource- and selfpreservation. Those reporting higher magnitudes of participation also reported greater food and income insecurity. Food and income insecurity may be a motivation to participate in MPA initiatives, due to the desire to safeguard resources. As Pollnac et al. (2001) found that perceived crisis predicted perceived MPA success, this finding similarly suggests that perceived food insecurity might motivate resource users to contribute to MPA initiatives. Perception of personal benefit from marine sanctuaries was additionally related to participation. The choice to participate is likely a trade-off between time spent and benefits received for resource users in the Philippines. Perceptions of benefit were also positively related to perceptions of MPA success, suggesting the possibility of feedback that encourages participation and builds positive perceptions of marine sanctuaries.

Previous research has shown that those who participate in citizen science programs have stronger pro-environmental tendencies compared to the general population (Brossard et al. 2005; Crall et al. 2013). The results of this study indicate closer self-identity with nature among those with increased magnitude of participation. In addition, the observed relationship between participation and the "Control" conservation beliefs factor suggests that participation in MPA initiatives may be driven, at least in part, by interest in environmentally correct efforts to manage and protect local resources. 
It is likely that two separate and complementary processes were underway: (1) individuals chose to participate based on strong concern for environmental issues, and (2) participation resulted in increased environmental concern. Research has documented higher perceptions of self-efficacy among citizen science volunteers as a result of participation in a monitoring program (Johnson et al. 2014). As self-efficacy was reflected in our "Control" beliefs component, it is plausible that participation in marine protected area initiatives heightened belief in the ability to manage environmental impacts through personal action, which may result in positive feedbacks within the system.

Resource users who participated more were more likely to attribute conservation-related ecosystem service value to corals and mangroves and also to demonstrate scientifically correct ecological knowledge. Those with greater scientific knowledge may be more interested in conservation initiatives that advocate environmentally correct values, knowledge, and awareness. Additionally, participation likely provides a pathway that promotes the exchange of complex information and increases scientific knowledge among participants. The positive relationship between science-related participation and scientific knowledge among citizen science participants has been well documented (e.g. Johnson et al. 2014; Branchini et al 2015; Brossard et al. 2005). Participation in planning, monitoring, and training programs requires that practitioners and participants build common knowledge systems in order to better share information. In this way, participants may continue to build scientific knowledge that supports decisionmaking and management strategies.

As repeatedly demonstrated, establishing a sanctuary does not guarantee biological improvement and community support (e.g. Walmsley and White 2003; White et al. 2002). One of the principal challenges of MPA management is building trust and cooperation among stakeholders, as local disenchantment and conflict can derail the success of an MPA (Christie et al. 2009; Christie 2004; Cabigas et al. 2012). Community support, enforcement, and compliance are key factors that influence MPA success and positive ecological outcomes in MPAs in the Philippines (Pollnac and Seara 2011; Walmsley and White 2003). It is important to consider that if resource users do not perceive an MPA as successful, the likelihood of compliance and ecological success may be reduced. The findings in this study expand this understanding by underlining the importance of effective management and inclusive processes for promoting information exchange and desirable social-ecological conditions and provide empirical support for the argument that these processes can contribute to improving perceptions of MPA performance.

The consistently positive interrelationships observed in this analysis indicate that participation is a central factor that relates both to a range of social-ecological conditions and to perceptions of successful MPA management in developing country coastal communities. Programs seeking to increase stakeholder participation will likely face some level of dissatisfaction resulting from inevitable incongruences between expectations and outcomes. Some level of conflict is expected and must be accommodated in planning and management (Christie et al. 2009). Nevertheless, the strong positive relationship observed between the participation index and the MPA performance index empirically substantiates the argument that better engagement through participation in MPA planning and management can increase perceptions of marine sanctuary success. Furthermore, causal inferences based on theoretical relationships suggest that participatory processes may initiate or augment positive feedbacks between participation, social ecological factors, and MPA performance. The potential for feedbacks has encouraging implications for the continued use of project participation in management practices to improve social ecological conditions that benefit MPA performance.

\section{CONCLUSIONS}

Overall, this evaluation finds strong empirical support for approaches that enable community engagement through participatory mechanisms in MPA management. The results of this evaluation reinforce current inquiry into the value of participation in influencing MPA performance. This analysis indicates that resource user participation influences their perceptions of MPA performance, and that this finding must be interpreted in the context of interrelationships between participation and a range of social ecological factors, including:

- Demographics (age, education and gender), 
- Conservation beliefs related to human ability to control environmental impacts (scored from the "Control" beliefs factor) and close self-identity with nature,

- Food and income security and positive perceptions of benefits derived from MPAs, and

- Scientifically accurate ecological knowledge.

These findings support the continued development of participatory processes in MPA management in the context of high resource dependency in the Philippines. Participation has utility in influencing desirable social ecological conditions that foster perceptions of MPA success and in providing mechanisms for information exchange between resource users and practitioners. Systemic relationships reveal potential for positive feedbacks between participation and support of environmental management and marine sanctuaries.

Results suggest that a combination of participatory methods including community monitoring, training, enforcement, and process engagement can collectively build perceptions of MPA success. Managers and practitioners can improve their approach to engagement by increasing engagement of women, improving education opportunities, and increasing the capacity to combat regional food and income insecurity. Assessment reveals good regional support for these MPA initiatives and strong evidence of capacity- and knowledge-building through meaningful stakeholder engagement; however, significant challenges remain to ensure and sustain achievements in the region. 


\section{LITERATURE CITED}

Agardy T, di Sciara GN, Christie P (2011) Mind the Gap: Addressing the Shortcomings of Marine Protected Areas through Large Scale Marine Spatial Planning. Marine Policy 35(2):226-232

Asher HB (1983) Causal modeling. Sage Publications, Newbury Park

Blalock HM (1972) Causal inferences in nonexperimental research. Norton, New York

Blalock HM (ed) (1971) Causal models in the social sciences. Aldine Atherton, Chicago

Branchini S, Meschini M, Covi C, Piccinetti C, Zaccanti F, Goffredo S (2015) Participating in a Citizen Science Monitoring Program: Implications for Environmental Education. PLoS ONE 10(7):e0131812

Brossard D, Lewenstein B, Bonney R (2005) Scientific Knowledge and Attitude Change: The Impact of a Citizen Science Project. Int J Sci Educ 27(9):1099-1121

Cabigas RB, Manzano LL, Nobukazu N (2012) Success and Failure of Marine Protected Area Management Affecting the Fish Catch by Adjacent Fishermen in Sarangani Bay, Mindanao, Philippines. S Pac Stud 33(1):1-24

Chess C, Purcell K (1999) Public Participation and the Environment: Do We Know What Works? Environ Sci Technol 33(16):2685-2692

Christie P (2004) Marine Protected Areas as Biological Successes and Social Failures in Southeast Asia. Am Fish Soc 42:155-164

Christie P, Bradford D, Garth R, Gonzalez B, Hostetler M, Morales O, Rigby R, Simmons B, Tinkam E, Vega G, Vernooy R, White N (2000) Taking Care of What We Have: Participatory Natural Resource Management on the Atlantic Coast of Nicaragua. University of Central America Center for Research and Documentation of the Atlantic Coast and the International Development Research Centre: Managua and Ottawa

Christie P, Pietri DM, Stevenson TC, Pollnac RB, Knight M, White AT (2016) Improving Human and Environmental Conditions through the Coral Triangle Initiative: Progress and Challenges. Curr Opin Environ Sustain 19:169181

Christie P, Pollnac RB, Oracion EG, Sabonsolin A, Diaz R, Pietri D (2009) Back to Basics: An Empirical Study Demonstrating the Importance of Local-Level Dynamics for the Success of Tropical Marine Ecosystem-Based Management. Coast Manag 37(3-4):349-373

Cinner JE (2007) Designing Marine Reserves to Reflect Local Socioeconomic Conditions: Lessons from LongEnduring Customary Management Systems. Coral Reefs 26(4):1035-1045

Chuenpagdee R, Pascual-Fernández JJ, Szeliánszky E, Alegret JL, Fraga J, Jentoft S (2013) Marine Protected Areas: Re-Thinking Their Inception. Marine Policy 39:234-240

Crall AW, Jordan R, Holfelder K, Newman GJ, Graham J, Waller DM (2013) The Impacts of an Invasive Species Citizen Science Training Program on Participant Attitudes, Behavior, and Science Literacy. Public Underst Sci 22(6):745-764

Dalton T, Forrester G, Pollnac RB (2012) Participation, Process Quality, and Performance of Marine Protected Areas in the Wider Caribbean. Environ Manag 49(6):1224-1237

Davis JL, Green JD, Reed A (2009) Interdependence with the Environment: Commitment, Interconnectedness, and Environmental Behavior. J Environ Psychol 29(2):173-80

Devantier L, Alcala A, Wilkinson C (2004) The Sulu-Sulawesi Sea: Environmental and Socioeconomic Status, Future Prognosis and Ameliorative Policy Options. Ambio 33(1/2):88-97

Evans RD, Russ GR, Kritzer JP (2008) Batch Fecundity of Lutjanus carponotatus (Lutjanidae) and Implications of NoTake Marine Reserves on the Great Barrier Reef, Australia. Coral Reefs 27(1):179-189

Gurney GG, Cinner JE, Sartin J, Pressey RL, Ban NC, Marshall NA, Prabuning D (2016) Participation in Devolved Commons Management: Multiscale Socioeconomic Factors Related to Individuals' Participation in CommunityBased Management of Marine Protected Areas in Indonesia. Environ Sci Policy 61:212-220

Gutiérrez NL, Hilborn R, Defeo O (2011) Leadership, Social Capital and Incentives Promote Successful Fisheries. Nature 470(7334):386-389

Hamilton M (2012) Perceptions of Fishermen towards Marine Protected Areas in Cambodia and the Philippines. Biosci Horiz 5:1-24

Hoelting KR, Hard CH, Christie P, Pollnac RB (2013) Factors Affecting Support for Puget Sound Marine Protected Areas. Fish Res 144:48-59

Johnson MF, Hannah C, Acton L, Popovici R, Karanth KK, Weinthal E (2014) Network Environmentalism: Citizen Scientists as Agents for Environmental Advocacy. Glob Environ Chang 29: 235-245

Juffe-Bignoli D, Burgess ND, Bingham H, Belle EMS, de Lima MG, Deguignet M, Bertzky B, Milam AN, MartinezLopez J, Lewis E, Eassom A, Wicander S, Geldmann J, van Soesbergen A, Arnell AP, O'Connor B, Park S, Shi YN, Danks FS, MacSharry B, Kingston N (2014) Protected Planet Report. UNEP-WCMC, Cambridge

Lester SE, Halpern BS, Grorud-Colvert K, Lubchenco J, Ruttenberg BI, Gaines SD, Airamé S, Warner RR (2009) Biological Effects within No-Take Marine Reserves: A Global Synthesis. Marine Ecol Prog Ser 384:33-46

Mackenzie J, Tan P-L, Hoverman S, Baldwin C (2012) The Value and Limitations of Participatory Action Research Methodology. J Hydrol 474:11-21 
Magdaong ET, Fujii M, Yamano H, Licuanan WY, Maypa A, Campos WL, Alcala AC, White AT, Apistar D, Martinez R (2014) Long-Term Change in Coral Cover and the Effectiveness of Marine Protected Areas in the Philippines: A Meta-Analysis. Hydrobiol 733(1):5-17

Martinez TA, McMullin SL (2004) Factors Affecting Decisions to Volunteer in Nongovernmental Organizations. Environ Behav 36(1):112-126

Mascia MB (2003) The Human Dimension of Coral Reef Marine Protected Areas: Recent Social Science Research and Its Policy Implications. Conserv Biol 17(2):630-632

McClanahan T, Davies J, Maina J (2005) Factors influencing resource users and managers' perceptions towards marine protected area management in Kenya. Environ Conserv 32(1):42-49

Muallil RN, Deocadez MR, Martinez RJS, Mamauag SS, Nañola CL, Aliño PM (2015) Community Assemblages of Commercially Important Coral Reef Fishes inside and Outside Marine Protected Areas in the Philippines. Reg Stud Marine Sci 1:47-54

Muro M and Jeffrey P (2008) A Critical Review of the Theory and Application of Social Learning in Participatory Natural Resource Management Processes. J Environ Plan Manag 51(3):325-44

Netemeyer RG, Bearden WO, Sharma S (2003) Scaling procedures: Issues and applications. Sage Publications, Thousand Oaks

Pietri D, Christie P, Pollnac RB, Diaz R, Sabonsolin A (2009) Information Diffusion in Two Marine Protected Area Networks in the Central Visayas Region, Philippines. Coast Manag 37(3-4):331-348

Pollnac RB, Christie P, Cinner JE, Dalton T, Daw TM, Forrester GE, Graham NAJ, McClanahan TR (2010) Marine Reserves as Linked Social-Ecological Systems. Proc Natl Acad Sci 107(43):18262-18265

Pollnac RB, Crawford BR, Gorospe MLG (2001) Discovering Factors That Influence the Success of CommunityBased Marine Protected Areas in the Visayas, Philippines. Ocean Coast Manag 44(11):683-710

Pollnac RB, Seara T (2011) Factors Influencing Success of Marine Protected Areas in the Visayas, Philippines as Related to Increasing Protected Area Coverage. Environ Manag 47(4):584-592

Pomeroy RS, Watson LM, Parks JE, Cid GA (2005) How Is Your MPA Doing? A Methodology for Evaluating the Management Effectiveness of Marine Protected Areas. Ocean Coast Manage 48(7):485-502

Price CA, Lee H-S (2013) Changes in Participants' Scientific Attitudes and Epistemological Beliefs during an Astronomical Citizen Science Project. J Res Sci Teach 50(7):773-801

Ram-Bidesi V (2015) Recognizing the Role of Women in Supporting Marine Stewardship in the Pacific Islands. Marine Policy 59: 1-8

Reed MS (2008) Stakeholder Participation for Environmental Management: A Literature Review. Biol Conserv 141(10):2417-2431

Roberts CM, Bohnsack JA, Gell F, Hawkins JP, Goodridge R (2001) Effects of Marine Reserves on Adjacent Fisheries. Science 294(5548):1920-1923

Rowe G, Frewer LJ (2000) Public Participation Methods: A Framework for Evaluation. Sci Technol Hum Values 25(1):3-29

Russ GR, Alcala AC (1999) Management Histories of Sumilon and Apo Marine Reserves, Philippines, and Their Influence on National Marine Resource Policy. Coral Reefs 18(4):307-319

Russ GR, Alcala AC, Maypa AP (2003) Spillover from marine reserves: the case of Naso vlamingii at Apo Island, the Philippines. Marine Ecol Prog Ser 264:15-20

Sala E, Costello C, Dougherty D, Heal G, Kelleher K, Murray JH, Rosenberg AA, Sumaila R (2013) A General Business Model for Marine Reserves. PLoS ONE 8(4):e58799

Simon HA (1957) Models of man, social and rational: Mathematical essays on rational human behavior in a social setting. Wiley, New York

Smith SL (2012) Toward Inclusive Co-Management: Factors Influencing Stakeholder Participation. Coast Manag 40(3):327-337

Toomey AH, Domroese MC (2013) Can Citizen Science Lead to Positive Conservation Attitudes and Behaviors? Hum Ecol Rev 20(1):50-62

Trimble M and Lázaro M (2014) Evaluation Criteria for Participatory Research: Insights from Coastal Uruguay. Environ Manag 54(1):122-37

Tupper M, Asif F, Garces LR, Pido MD (2015) Evaluating the Management Effectiveness of Marine Protected Areas at Seven Selected Sites in the Philippines. Marine Policy 56:33-42

Walmsley SF, White AT (2003) Influence of Social, Management and Enforcement Factors on the Long-Term Ecological Effects of Marine Sanctuaries. Environ Conserv 30(4):388-407

Webler T, Tuler S, Krueger R (2001) What Is a Good Public Participation Process? Five Perspectives from the Public. Environ Manag 27(3):435-450

Weeks R, Aliño PM, Atkinson S, Beldia P, Binson A, Campos WL, Djohani R, Green AL, Hamilton R, Horigue V, Jumin R, Kalim K, Kasasiah A, Kereseka J, Klein C, Laroya L, Magupin S, Masike B, Mohan C, Da Silva Pinto RM, Vave-Karamui A, Villanoy C, Welly M, White AT (2014) Developing Marine Protected Area Networks in the Coral Triangle: Good Practices for Expanding the Coral Triangle Marine Protected Area System. Coast Manag 42(2):183-205 
White AT, Courtney CA, Salamanca A (2002) Experience with Marine Protected Area Planning and Management in the Philippines. Coast Manag 30(1):1-26 